\title{
The Impact of Education and Residence on Current Use of Contraception in Ethiopian Women
}

\author{
Arif Ahmed ${ }^{1} \&$ Mohammad S. Zahangir ${ }^{2}$ \\ ${ }^{1}$ Department of Statistics, Stockholm University, Stockholm, Sweden \\ ${ }^{2}$ Department of Statistics, University of Chittagong, Chittagong-4331, Bangladesh \\ Correspondence: Arif Ahmed, Department of Statistics, Stockholm University, Stockholm, Sweden. Tel: \\ 46-700-454-557. E-mail: arif.stat.su@gmail.com
}

Received: June 13, 2019 Accepted: July 24, 2019 Online Published: July 31, 2019

doi:10.5539/gjhs.v11n9p182

URL: https://doi.org/10.5539/gjhs.v11n9p182

\begin{abstract}
Background: Maternal and infant mortality is high in Ethiopia. An underlying cause of maternal and infant mortality is unintended pregnancy, which is inversely associated with contraceptive use. Hence, the use of contraception can necessarily be increased to reduce the mortality rate of mother and infant.
\end{abstract}

Objectives: This study aims to examine the effect of educational attainment and place of residence on contraceptive use among Ethiopian women of childbearing ages.

Methods: Data are obtained from the 2016 Ethiopian Demographic and Health Survey (EDHS) and total 10223 women aged 15-49 years are analyzed in this study. Both unadjusted and adjusted multivariate logistic regression models are employed to examine the effect of exposure variables on contraceptive use.

Results: It can be seen that only around $36 \%$ of Ethiopian women used any of the contraceptive methods. In the case of contraceptive use, a significantly higher odds is observed for women with secondary or higher education with respect to those who were illiterate (e.g., OR $=1.51,95 \% \mathrm{CI}: 1.19-1.93$ after adjusting for total children ever born, number of living children, desire of more children, wealth index, respondent currently working, region and religion; and $\mathrm{OR}=2.53,95 \% \mathrm{CI}$ : 2.05-3.13 for unadjusted model). Urban women had also a significantly higher odds for contraceptive use than their rural counterparts (OR $=1.89,95 \% \mathrm{CI}$ : $1.42-2.51$ by adjusted model for the above confounders, and $\mathrm{OR}=2.22,95 \% \mathrm{CI}: 1.81-2.73$ by unadjusted model).

Conclusion: The findings reveal that both educational improvement and urbanization may increase the use of contraception among women in Ethiopia.

Keywords: contraception use, education, residence, logistic regression, odds ratio

\section{Introduction}

A disappointingly high maternal mortality exists worldwide (WHO, 2018). Pregnancy and childbirth associated causes take around 830 lives of women daily globally. Almost all (99\%) of these deaths take place in the developing countries. Sub-Saharan Africa and South-Asia cover more than half and around one-third of these deaths respectively (WHO, 2018). The pregnancy related maternal mortality in Ethiopia was 412 per 100000 live births, based on Ethiopian Demographic and Health Survey (CSA, 2016).

A prime cause of higher maternal and infant mortality as well as abortions is unintended pregnancy (Doherty et al., 2018). The rate of unintended pregnancy in Ethiopia was 38\%, where induced abortion occurred in $13 \%$, in 2014 (Moore et al., 2016). Additionally, a more recent study, performed in 2017, found a bit higher rate (41.5\%) of unintended pregnancy among women at Arsi Negele district in Ethiopia (Fite, Mohammedamin, \& Abebe, 2018). One of the important reasons for unintended pregnancies might be the lack of, inconsistent or incorrect use of effective contraceptive methods (CDC, 2016). For example, due to unavailability of contraception about $20 \%$ of the unwanted pregnancy occurred in women in refugee camps in Ethiopia, and more than three-quarter of those resulted in maternal mortality (Gebrecherkos et al., 2018). Moreover, a high interruption of modern contraceptive use was observed among reproductive aged Ethiopian women (Belete, Zemene, Hagos, \& Yekoye, 2018). Such of many unintended pregnancies, still birth, and neonatal and maternal deaths can be averted by using contraception regularly (Berhan \& Berhan, 2014; Godefay, Byass, Graham, Kinsman, \& Mulugeta, 2015). 
A noticeable family planning success is under way in Ethiopia. Over the period 1990 to 2011, modern contraceptive use in Ethiopia increased nine-fold among married women aged $15-49$ years, $2.9 \%$ in 1990 to $27.3 \%$ in 2011 (Olson \& Piller, 2013). However, a very low contraceptive prevalence $(<20.0 \%)$ was revealed in rural Ethiopia (Debebe, Andualem Limenih, \& Biadgo, 2017). Though the modern contraceptive prevalence was increased in reproductive aged Ethiopian women who were either married or in union, still it is very low compared to other African countries. For instance, it is $44.8 \%$ in Zambia in 2013-2014, 53.2\% in Kenya in 2014, 47.0\% in Northern Africa in 2000-2015, 59.0\% in Southern Africa in 2000-2015 (Tsui, Brown, \& Li, 2017). Moreover, the contraceptive prevalence in outside of African region was, for example, $57.9 \%$ in Indonesia in $2012,70.0 \%$ in America in 2000-2015, 58.0\% in Europe in 2000-2015, 67.0\% in Latin America and Caribbean in 2000-2015 (Tsui, Brown, \& Li, 2017), and 51.8\% in Asia in 2017 (Cahill et al., 2018).

Education, especially women's education may play an influential role in order to use contraception successfully. Weitzman (2017) stated that women's education improves cognitive skills, awareness about health, financial resources and decision-making power. It provides improved access to the mass media (radio, TV and newspaper) (Jahan, Rahman, Chowdhury, Chowdhury, \& Huq, 2017), knowledge and attitude about family planning, access to contraception, correct use of contraception, and finally promotes contraceptive use (Kasa, Tarekegn, \& Embiale, 2018; Shapiro \& Tambashe, 1994).

Beside education, urbanization increases the awareness among couples about family planning and related issues. A lower access to mass media, health information resources, magazines, and scientific articles is prevalent in rural compared to urban residents. The lower access to mass media narrows down the access to health information among rural individuals (Chen et al., 2019). Oluwasanu, John-Akinola, Desmennu, Oladunni and Adebowale (2019) observed that more access to family planning information improves modern contraceptive use. Apparently, urbanization and women's education play a positive role to reduce short birth space and unwanted pregnancies with an increasing contraceptive use, as a result, controls unsafe abortions and maternal mortality (Weitzman, 2017). Based on the previous studies, other risk factors are wealth index, employment status, region (Mandiwa, Namondwe, Makwinja, \& Zamawe, 2018), religion (Mekonnen \& Worku, 2011), desire for more children, number of living children and parity (Hossain, Khan, Ababneh, \& Shaw, 2018).

Very little is known about the impact of education and place of residence on contraception use. To our knowledge no study is available on this topic based on the latest nationally representative data in Ethiopia. This study aims to minimize the research gap with some contribution through examining how much effect education and place of residence have on contraceptive use applying the latest Ethiopian Demographic and Health Survey data to enhance the intervention strategies. Based on the findings from previous researches and conceptual framework, we formulated the hypothesis that women with secondary or higher educational attainments and women living in urban areas would be more likely to use contraception than their respective counterparts.

\section{Material and Methods}

\subsection{Source of Data}

This study uses the 2016 Ethiopian Demographic and Health Survey (EDHS) data. The survey was conducted by Central Statistical Agency (CSA). The CSA was collaborated "with the Federal Ministry of Health (FMoH) and the Ethiopian Public Health Institute (EPHI) with technical assistance from ICF International, and financial as well as technical support from development partners". EDHS is a nationally representative and retrospective survey, which is carried out by a stratified two-stage cluster sampling design. The sampling unit at the first stage was census enumeration areas and the sampling unit at the second stage was households. The sample comprised 645 enumeration areas (202 in urban areas and 443 in rural areas) and 18008 households (CSA, 2016).

Data were collected using questionnaires on household and women. Eligible women for individual interviews were identified applying household questionnaire. Further, data from all eligible women aged 15-49 were collected with the women's questionnaire. Pretesting of the questionnaires were done to ensure that the questions were clear and could be understood by the respondents. Pretesting of the questionnaire took place "from 1 to 28 October 2015, in Bishoftu at the Asham African Training Centre". Later, the questionnaires were modified with the gathered knowledge from the pretest. Data were collected using computer assisted personal interviewing (CAPI) method that used the CSPro software (mobile version). Responses from individuals were recorded using tablet computers at the time of interviews. The interview was carried on 15683 women aged 15-49 years during the period 18 January 2016 to 27 June 2016. The overall response rate was $95 \%$ (CSA, 2016).

\subsection{Data Extraction and Analytical Sample}

Women who were not married but living with partner (1.4\% in 2016) were identified in the group of those who 
were taking children. Consideration of those women should be required under family planning too. Thus, out of total 15683 eligible women in the EDHS-2016 data, this study has extracted 10014 weighted number of married women plus 209 weighted number of unmarried women, who were living with partner. That is, total 10223 women are included in this study. As there is no missing value in the studied variables, the analysis is carried on all 10223 women.

\subsection{Variables}

"Current contraceptive method" is considered the outcome variable. In order to compute the variable, respondents were asked "are you or your partner currently doing something or using any method to delay or avoid getting pregnant?" The answer was coded as 0 : not using and 1: using contraception. The variable with mentioning available contraceptive methods is shown in Table 1. Respondent's educational attainment categorized as illiterate, primary, and secondary and above, and type of place of residence categorized as urban and rural and are used as the exposure variables. Moreover, the explanatory variables that are used as confounders (data not presented) are presented in Table 2.

\section{Analysis}

By using the binary logistic regression technique, the odds ratios (ORs) and $95 \%$ confidence intervals are generated for both the unadjusted and adjusted models. The proc survey logistic procedure in SAS version 9.4 is used to fit the multivariate logistic regression model. Four different models are used. First, an unadjusted model, model $^{\mathrm{a}}$. Second, model ${ }^{\mathrm{b}}$, adjusted for total children ever born, number of living children and desire of more children. Third, model ${ }^{c}$, adjusted for the confounders used in model ${ }^{b}$ plus wealth index and respondent currently working. Fourth, model ${ }^{\mathrm{d}}$, adjusted for the confounders used in model $\mathrm{l}^{\mathrm{c}}$ plus region and religion. Findings with $\mathrm{p}<0.05$ are considered as statistically significant. The reference categories are selected to those categories which have the lowest proportion of contraceptive use based on cross tabulation (data not presented). Sampling weights are used in the analysis because of the non-proportional allocation of the sample to the different regions and their urban and rural areas to ensure the actual representativeness of the survey results at the national and regional level. No multicollinearity among the independent variables was observed, since we received the variance inflation factor (VIF) $<5.0$ (Chatterjee and Hadi, 2006), which is the presumption of using logistic regression.

\section{Results}

Table 1. Percentage and cumulative percentage of women by contraceptive methods used based on EDHS 2016 $(\mathrm{n}=10223)$.

\begin{tabular}{llll}
\hline Contraceptive use & Contraceptive methods & Percentage & Cumulative percentage \\
\hline Used & Pill & 1.84 & 1.84 \\
& IUD & 2.04 & 3.88 \\
Injections & 22.77 & 26.65 \\
Male condom & 0.06 & 26.71 \\
Female sterilization & 0.42 & 27.13 \\
Periodic abstinence & 0.52 & 27.65 \\
Withdrawal & 0.11 & 27.76 \\
Implants/Norplant & 7.89 & 35.65 \\
Lactational amenorrhea (LAM) & 0.15 & 35.80 \\
Eot used & Emergency contraception & 0.03 & 35.83 \\
& Standard days method (SDM) & 0.06 & 35.89 \\
& & 64.11 & 100.00 \\
\hline
\end{tabular}

Table 1 represents the percentage of Ethiopian women of reproductive ages by contraceptive methods either used or not. Though almost all (98\%) of women or couples had knowledge about any method of family planning (data not shown in the table), only slightly more than one-third (35.88\%) of them were used any of a contraceptive method in 2016. Of 11 different available methods, 'injections' was the most practiced method in Ethiopia $(22.77 \%)$. The second most practiced method was implants/norplant $(7.89 \%)$, followed by IUD $(2.04 \%)$, pill 
(1.84\%), periodic abstinence $(0.52 \%)$ and female sterilization $(0.42 \%)$, respectively. However, the percentages of all other practiced methods were very negligible (see Table 1 ).

Table 2. Percentage and cumulative percentage of women by categories of independent variables $(n=10223)$

\begin{tabular}{|c|c|c|c|}
\hline Name of variables & Category & Percentage & Cumulative percentage \\
\hline \multirow{2}{*}{ Residence } & Urban & 16.2 & 16.2 \\
\hline & Rural & 83.8 & 100.0 \\
\hline \multirow{3}{*}{ Education } & No education & 61.2 & 61.2 \\
\hline & Primary & 28.3 & 89.5 \\
\hline & Secondary and above & 10.5 & 100.0 \\
\hline \multirow{3}{*}{ Region } & Tigray/Afar/Amhara & 31.0 & 31.0 \\
\hline & Oromia & 39.0 & 70.0 \\
\hline & Others & 30.0 & 100.0 \\
\hline \multirow{3}{*}{ Religion } & Orthodox-Christian & 40.5 & 40.5 \\
\hline & Muslim & 34.6 & 75.1 \\
\hline & Others & 24.9 & 100 \\
\hline \multirow{5}{*}{ Wealth index ${ }^{a}$} & Poorest & 19.1 & 19.1 \\
\hline & Poorer & 20.3 & 39.4 \\
\hline & Middle & 20.1 & 59.5 \\
\hline & Richer & 19.6 & 79.1 \\
\hline & Richest & 20.9 & 100.0 \\
\hline \multirow{4}{*}{ Total children ever born } & $0-1$ child & 22.7 & 22.7 \\
\hline & $2-3$ children & 26.6 & 49.3 \\
\hline & $4-6$ children & 30.4 & 79.7 \\
\hline & $7 \&$ more children & 20.3 & 100.0 \\
\hline \multirow{4}{*}{ Number of living children } & No living children & 9.0 & 9.0 \\
\hline & $1-2$ children & 30.7 & 39.7 \\
\hline & $3-5$ children & 38.5 & 78.2 \\
\hline & $6 \&$ above children & 21.8 & 100 \\
\hline \multirow{4}{*}{ Desire for more children } & Wants within 2 years & 17.5 & 17.5 \\
\hline & Wants after $2+$ years & 35.8 & 53.3 \\
\hline & Doesn't want any more children & 36.3 & 89.6 \\
\hline & Have no plan or sterilized & 10.4 & 100.0 \\
\hline \multirow{2}{*}{ Respondent currently working } & No & 69.1 & 69.1 \\
\hline & Yes & 30.9 & 100.0 \\
\hline
\end{tabular}

${ }^{\text {a }}$ Principal component analysis was used to generate scores for the household assets. The household score was used to compile the wealth quintiles for each member of the household. The wealth quintiles were categorized into five equal category, such as poorest, poorer, middle, richer, and richest (CSA, 2016).

Table 2 represents the percentage of women belonging to each category of independent variables. Of rural and urban residents, more than four-fifths (83.8\%) lived in rural areas. Much more than half $(61.2 \%)$ of women had no formal education and only $10.5 \%$ of them had secondary or higher education. According to religious belief, around $40 \%$ of women were Orthodox-Christian, followed by Muslim (34.6\%) and other religions (24.9\%). Considering financial solvency, $40.0 \%$ of women were poor (poorest and poorer) and $40.5 \%$ of them were rich (richer and 
richest). Around half of reproductive aged women had at least four children ever born. Of all women, $9.0 \%$ had no living children and about $60.0 \%$ had at least three living children. More than one-third (36.3\%) of women wanted no more children. Each three or slightly more than three in ten women $(30.9 \%)$ were engaged in paid works.

Table 3. The association between exposure variables (education and residence) and contraceptive use in Ethiopian women based on logistic regression analysis $(\mathrm{n}=10223)$

\begin{tabular}{|c|c|c|c|c|}
\hline \multirow{3}{*}{ Exposure variables } & \multicolumn{4}{|c|}{ Current contraceptive use } \\
\hline & Model $^{\mathrm{a}}$ & Model $^{\mathrm{b}}$ & Model $^{\mathrm{c}}$ & Model $^{\mathrm{d}}$ \\
\hline & OR $(95 \% \mathrm{CI})$ & OR $(95 \% \mathrm{CI})$ & OR $(95 \% \mathrm{CI})$ & OR $(95 \% \mathrm{CI})$ \\
\hline \multicolumn{5}{|l|}{ Education } \\
\hline No education (Ref.) & 1.00 & 1.00 & 1.00 & 1.00 \\
\hline Primary & $1.45(1.24,1.70)$ & $1.30(1.08,1.55)$ & $1.10(0.91,1.31)$ & $1.18(0.98,1.41)$ \\
\hline Secondary \& above & $2.53(2.05,3.13)$ & $2.51(1.97,3.19)$ & $1.59(1.24,2.04)$ & $1.51(1.19,1.93)$ \\
\hline \multicolumn{5}{|l|}{ Residence } \\
\hline Rural (Ref.) & 1.00 & 1.00 & 1.00 & 1.00 \\
\hline Urban & $2.22(1.81,2.73)$ & $2.20(1.78,2.72)$ & $1.97(1.46,2.66)$ & $1.89(1.42,2.51)$ \\
\hline
\end{tabular}

Note. Model $^{\mathrm{a}}$ : unadjusted. Model $^{\mathrm{b}}$ : adjusted for total children ever born, number of living children and desire of more children; Model $^{\mathrm{c}}$ : adjusted for the confounders used in model ${ }^{\mathrm{b}}+$ wealth index and respondent currently working; and Model ${ }^{\mathrm{d}}$ : adjusted for the confounders used in $\operatorname{model}^{\mathrm{c}}+$ region and religion. Significance level: $\mathrm{p}<0.05$ are in bold. Ref. stands for reference category.

An association between exposure variables (education and place of residence) and contraceptive use is shown in Table 3. The unadjusted model $\left(\right.$ model $\left.^{\mathrm{a}}\right)$ reveals that women with any level of schooling were significantly higher likely to use contraception than the illiterate women $(\mathrm{OR}=1.45,95 \% \mathrm{CI}: 1.24-1.70$ for primary and $\mathrm{OR}=2.53$, 95\% CI: $2.05-3.13$ for secondary or higher educated women). This association remains significant even after the subsequent adjustment for confounders in model ${ }^{\mathrm{b}}$, model ${ }^{\mathrm{c}}$ and $\operatorname{model}^{\mathrm{d}}$. However, in model ${ }^{\mathrm{c}}$ and model ${ }^{\mathrm{d}}$, only secondary or higher educated women were significantly higher likely to contraceptive use than illiterate women. A higher reduction in odds ratios for secondary or higher education is observed in $\operatorname{model}^{\mathrm{c}}(\mathrm{OR}=1.59,95 \% \mathrm{CI}$ : 1.24 2.04 than model $^{\mathrm{b}}(\mathrm{OR}=2.51,95 \%$ CI: $1.97-3.19)$ and a slight reduction in $\operatorname{model}^{\mathrm{d}}(\mathrm{OR}=1.51,95 \%$ CI: $1.19-1.93)$ than $\operatorname{model}^{\mathrm{c}}(\mathrm{OR}=1.59,95 \% \mathrm{CI}: 1.24-2.04)$. Notice that the association in model ${ }^{\mathrm{b}}$ is along with the confounded factors (e.g., total children ever born, number of living children and desire of more children), further, model ${ }^{c}$ is adjusted additionally for wealth index and respondent currently working. Apparently, wealth index and respondent currently working are strong confounders. Moreover, model ${ }^{\mathrm{d}}$ is adjusted additionally for region and religion than those in model ${ }^{\mathrm{c}}$. That is, region and religion are moderate confounders.

In case of place of residence, the unadjusted model reveals that urban women were significantly more likely to use contraception than rural women (model ${ }^{\mathrm{a}}$ : $\mathrm{OR}=2.22,95 \% \mathrm{CI}: 1.81-2.73$ ). As before, this association is also found to be significant in model ${ }^{\mathrm{b}}$, model ${ }^{\mathrm{c}}$ and $\operatorname{model}^{\mathrm{d}}$ and the models provide similar findings. That is, the odds ratio is much more reduced in $\operatorname{model}^{\mathrm{c}}\left(\mathrm{OR}=1.97,95 \% \mathrm{CI}\right.$ : 1.46-2.6) than $\operatorname{model}^{\mathrm{b}}(\mathrm{OR}=2.20,95 \% \mathrm{CI}: 1.78-2.72)$ and slightly reduced in $\operatorname{model}^{\mathrm{d}}(\mathrm{OR}=1.89,95 \% \mathrm{CI}: 1.42-2.51)$ than $\operatorname{model}^{\mathrm{c}}(\mathrm{OR}=1.97,95 \% \mathrm{CI}$ : 1.46-2.66). Indeed, as the adjusted factors wealth index and respondent currently working are strong, and region and religion are moderate confounders in the association of exposure variables and contraceptive use. An overall test result for all parameters in the model is found from the output on testing the global null hypothesis. The value of $F$ indicates that the model has a statistically significant predictive capability (data not shown).

\section{Discussion}

The findings from multivariate logistic regression analysis expose that female education is positively associated with contraceptive use. Tiruneh, Chuang, Ntenda and Chuang (2016) also found a similar finding based on EDHS 2011 data. However, for women with secondary or higher education, they obtained a slightly lower odds ratio (OR $=1.34)$ compared to the current study $\left(\mathrm{OR}=1.51\right.$ by $\left.\mathrm{model}^{\mathrm{d}}\right)$. Another study also observed that women with secondary or higher education are more likely to contraceptive use with respect to illiterate women in Ethiopia (Alemayehu et al., 2018). In addition to secondary or higher education, women with primary education are 
significantly higher likelihood to contraceptive use than illiterate women in Northern Ethiopia (Medhanyie et al., 2017). Indeed, with respect to illiterates, educated women have better knowledge regarding the advantages of family planning and have more accesses and utilizations of it (Apanga \& Adam, 2015).

Women who live in urban areas are almost two times higher likely to contraceptive use than rural women. Alemayehu et al. (2018) also found the similar odds ratio $(\mathrm{OR}=1.91)$ for contraceptive use among women in urban areas compared to their rural counterparts. Another study also noticed that urban women are two times more prone to contraceptive use than rural women in Northern Ethiopia (Medhanyie et al., 2017). An explanation of higher contraceptive use among urban women can be that urban dwellers have more access to health information through several sources including mass media (Musa, Assefa, Weldegebreal, Mitiku, \& Teklemariam, 2016). Another cause of that can be the majority of urban women are from egalitarian society and rural women from patriarchy. In fact, patriarchy women are more reliable on their husbands' in taking decision regarding contraceptive use as they have low education and have no economic capability (Bogale, Wondafrash, Tilahun, \& Girma, 2011).

The current study further reveals that wealth index and respondent currently working have strongly positive effect on contraceptive use. Moreover, the effect of region and religion on contraceptive use is significant to some extent. The findings are consistent with other studies. For example, Subramanian, Mcgrath, Ndlovu and Gafos (2008) and Tiruneh et al. (2016) found that socioeconomic status and employment status have significant positive effects on the contraceptive use in Ethiopia. A study on reproductive aged Zambian women also exposed that wealth index is a powerful predictor of contraceptive use (Mutombo \& Bakibinga, 2014). Moreover, the use of contraception among wealthier women in Guatemala is higher likely than their poor counterparts (Grace, 2010). A positive effect of employment status on contraceptive use was observed in Bangladeshi women; consequently, the improvement of contraceptive prevalence might be possible by creating jobs for women (Islam, Mondal, \& Khatun, 2016). In comparison with non-Muslim, Muslim women are less likely to contraceptive use as they usually desire and take more children (Morgan, Stash, Smith, \& Mason, 2002; Musa et al., 2016; Tiruneh et al., 2016). There was observed regional differences in contraceptive use in Ethiopia. The difference in contraceptive use across regions may be due to migrated people. For example, pastoralist people who migrate seasonally in Afar and Somali region and reside in rural and underdeveloped areas. As a result, they get less access to family planning tools (Tiruneh et al., 2016).

\subsection{Strengths}

The study has some strengths. First, it includes a large nationally representative sample. Hence, the results might be generalizable for this age group. Second, the studied variables have no missing values. Thus, the results found in this research are not affected by missing values. Third, the data is analyzed according to the complex survey design, i.e., using stratum, cluster, and sampling weights, so the results seem unbiased.

\subsection{Limitations}

This research work has some limitations. Firstly, the EDHS data are self-reported; thus, it may suffer from misreporting bias. Secondly, the nature of the data is cross-sectional and thus, the scope to interpret causal association is limited. Lastly, due to limited number of variables in the EDHS data, the study was not able to examine a full array of factors related to contraceptive behavior, particularly the psychological and social factors.

\section{Conclusion}

It appears that, still, there is a lower rate of contraceptive use in Ethiopia. The government and other non-governmental organizations should take more effective steps to improve female education as well as urbanization, results in increasing contraceptive use. The use of contraception can also be increased through enhancing the employment sector for women. Additionally, to make the practice of contraception more common throughout the country, especially in rural Ethiopia, the government should serve the family planning tools by a nominal cost to reproductive aged women. Contraceptive use might be improved with some special cares like making aware about lactational amenorrhea (LAM), periodic abstinence, standard days' method (SDM) and withdrawal, which are quite natural methods and free of costs. In fine, it is required a massive family planning program in Ethiopia, that is, various national and international campaigns about family planning may increase the contraceptive use in Ethiopian women.

\section{Acknowledgements}

The authors' are thankful to Ethiopian Demographic and Health Survey (EDHS) authority for collecting such a good dataset that was suitably used in this study. 


\section{Financial Support}

No financial support is received for this research work.

\section{Ethical Considerations}

The procedures of data collections were granted by the National Research Ethics Review Committee (NRERC) at the Ministry of Science and Technology, the Ethiopia Health and Nutrition Research Institute (EHNRI) Review Board, the institutional Review Board of International Classification of Functioning (ICF), and the Centers for Disease Control and Prevention (CDC). Each respondent was agreed and signed to provide information at the start of the individual interview.

\section{Competing Interests Statement}

Author's declare that they have no significant competing financial, professional, or personal interests that might have influenced the performance or presentation of the work described in this manuscript.

\section{References}

Alemayehu, G. A., Fekadu, A., Yitayal, M., Kebede, Y., Abebe, S. M., Ayele, T. A., ... Biks, G. A. (2018). Prevalence and determinants of contraceptive utilization among married women at Dabat Health and Demographic Surveillance System site, northwest Ethiopia. BMC Women's Health, 18(1), 1-7. https://doi.org/10.1186/s12905-018-0611-3

Apanga, P. A., \& Adam, M. A. (2015). Factors influencing the uptake of family planning services in the Talensi district, Ghana. Pan African Medical Journal, 20, 1-9. https://doi.org/10.11604/pamj.2015.20.10.5301

Belete, N., Zemene, A., Hagos, H., \& Yekoye, A. (2018). Prevalence and factors associated with modern contraceptive discontinuation among reproductive age group women, a community based cross-sectional study in Humera town, northern Ethiopia. BMC Women's Health, 18(1), 1-8. https://doi.org/10.1186/s12905-018-0663-4

Bogale, B., Wondafrash, M., Tilahun, T., \& Girma, E. (2011). Married women's decision making power on modern contraceptive use in urban and rural southern Ethiopia. BMC Public Health, 11(1), 342. https://doi.org/10.1186/1471-2458-11-342

Cahill, N., Sonneveldt, E., Stover, J., Weinberger, M., Williamson, J., Wei, C., ... Alkema, L. (2018). Modern contraceptive use, unmet need, and demand satisfied among women of reproductive age who are married or in a union in the focus countries of the Family Planning 2020 initiative: a systematic analysis using the Family $\begin{array}{lllll}\text { Planning Estimation Tool. The } & \text { 8ancet, }\end{array}$ https://doi.org/10.1016/S0140-6736(17)33104-5

CDC. (2016). Reproductive Health. Contraception. Unintended Pregnancy Prevention. Retrieved from Centers for Disease Control and Prevention website: https://www.cdc.gov/reproductivehealth/contraception/unintendedpregnancy/index.htm

Chen, X., Orom, H., Hay, J. L., Waters, E. A., Schofield, E., Li, Y., \& Kiviniemi, M. T. (2019). Differences in Rural and Urban Health Information Access and Use. Journal of Rural Health, 35(3), 405-417. https://doi.org/10.1111/jrh.12335

CSA. (2016). Central Statistical Agency/CSA/Ethiopia and ICF. 2016. Ethiopia Demographic and Health Survey 2016. Addis Ababa, Ethiopia, and Rockville, Maryland, USA: CSA and ICF. Retrieved from https://dhsprogram.com/pubs/pdf/FR328/FR328.pdf

Debebe, S., Andualem Limenih, M., \& Biadgo, B. (2017). Modern contraceptive methods utilization and associated factors among reproductive aged women in rural Dembia District, northwest Ethiopia: Community based cross-sectional study. International Journal of Reproductive Biomedicine (Yazd, Iran), 15(6), 367-374.

Doherty, K., Arena, K., Wynn, A., Offorjebe, O. A., Moshashane, N., Sickboy, O., ... Morroni, C. (2018). Unintended Pregnancy in Gaborone. Botswana African Journal of Reproductive Health, 22(2), 77. https://doi.org/10.29063/ajrh2018/v22i2.8

Fite, R. O., Mohammedamin, A., \& Abebe, T. W. (2018). Unintended pregnancy and associated factors among pregnant women in Arsi Negele Woreda, West Arsi Zone, Ethiopia. BMC Research Notes, 11(1), 1-7. https://doi.org/10.1186/s13104-018-3778-7

Gebrecherkos, K., Gebremariam, B., Gebeyehu, A., Siyum, H., Kahsay, G., \& Abay, M. (2018). Unmet need for modern contraception and associated factors among reproductive age group women in Eritrean refugee 
camps, Tigray, north Ethiopia: a cross-sectional study. BMC Research Notes, 11(1), 1-6. https://doi.org/10.1186/s13104-018-3956-7

Grace, K. (2010). Contraceptive use and intent in Guatemala. Demographic Research, 23(12), 335-364. https://doi.org/10.4054/DemRes.2010.23.12

Hossain, M., Khan, M., Ababneh, F., \& Shaw, J. (2018). Identifying factors influencing contraceptive use in Bangladesh: Evidence from BDHS 2014 data. BMC Public Health, 18(1), 1-14. https://doi.org/10.1186/s12889-018-5098-1

Islam, A. Z., Mondal, N. I., \& Khatun, M. L. (2016). Prevalence and Determinants of Contraceptive use among Employed and Unemployed Women in Bangladesh. Int $J$ MCH AIDS. 5(2), 92-102. https://doi.org/10.21106/ijma.83

Jahan, Y., Rahman, S. M. A., Chowdhury, A. S., Chowdhury, S., \& Huq, K. E. (2017). Trends in mass media exposure upon women: A review of Bangladesh Demographic and Health Survey. Global Journal of Medicine and Public Health, 6(2).

Kasa, A. S., Tarekegn, M., \& Embiale, N. (2018). Knowledge, attitude and practice towards family planning among reproductive age women in a resource limited settings of Northwest Ethiopia. BMC Research Notes, 11(1), 7-12. https://doi.org/10.1186/s13104-018-3689-7

Mandiwa, C., Namondwe, B., Makwinja, A., \& Zamawe, C. (2018). Factors associated with contraceptive use among young women in Malawi: analysis of the 2015-16 Malawi demographic and health survey data. Contraception and Reproductive Medicine, 3(1), 1-8. https://doi.org/10.1186/s40834-018-0065-x

Medhanyie, A. A., Desta, A., Alemayehu, M., Gebrehiwot, T., Abraha, T. A., Abrha, A., \& Godefay, H. (2017). Factors associated with contraceptive use in Tigray, North Ethiopia. Reproductive Health, 14(27), 1-11. https://doi.org/10.1186/s12978-017-0281-x

Mekonnen, W., \& Worku, A. (2011). Determinants of low family planning use and high unmet need in Butajira District, South Central Ethiopia. Reproductive Health, 8(37). https://doi.org/10.1186/1742-4755-8-37

Moore, A. M., Gebrehiwot, Y., Fetters, T., Wado, Y. D., Bankole, A., Singh, S., ... Getachew, Y. (2016). The estimated incidence of induced abortion in Ethiopia, 2014: Changes in the provision of services since 2008. International Perspectives on Sexual and Reproductive Health, 42(3), 111-120. https://doi.org/10.1363/42e1816

Morgan, P. S., Stash, S., Smith, H. E., \& Mason, K. O. (2002). Muslim and Non-Muslim Differences in Female Autonomy and Fertility: Evidence from Four Asian Countries. Population and Development Review, 28(3), 515-537.

Musa, A., Assefa, N., Weldegebreal, F., Mitiku, H., \& Teklemariam, Z. (2016). Factor associated with experience of modern contraceptive use before pregnancy among women who gave birth in Kersa HDSS, Ethiopia. BMC Public Health, 16(1), 1-6. https://doi.org/10.1186/s12889-016-3292-6

Mutombo, N., \& Bakibinga, P. (2014). The effect of joint contraceptive decisions on the use of Injectables, Long-Acting and Permanent Methods (ILAPMs) among married female (15-49) contraceptive users in Zambia: a cross-sectional study. Reproductive Health, 11(51), 1-8.

Olson, D. J., \& Piller, A. (2013). Ethiopia: An Emerging Family Planning Success Story. Studies in Family Planning, 44(4), 445-459.

Oluwasanu, M. M., John-Akinola, Y. O., Desmennu, A. T., Oladunni, O., \& Adebowale, A. S. (2019). Access to Information on Family Planning and Use of Modern Contraceptives Among Married Igbo Women in Southeast, Nigeria. International Quarterly of Community Health Education. https://doi.org/10.1177/0272684X18821300

Shapiro, D., \& Tambashe, B. O. (1994). The Impact of Women's Employment and Education on Contraceptive use and Abortion in Kinshasa, Zaire. Studies in Family Planning, 25(2), 96-110. https://doi.org/10.2307/2138087

Subramanian, L., Mcgrath, N., Ndlovu, H., \& Gafos, M. (2008). Family planning methods among women in a vaginal microbicide feasibility study in rural KwaZulu-Natal, South Africa. Afr J Reprod Health; 12(2), 45-63.

Tiruneh, F. N., Chuang, K. Y., Ntenda, P. A. M., \& Chuang, Y. C. (2016). Factors associated with contraceptive use and intention to use contraceptives among married women in Ethiopia. Women and Health, 56(1), 1-22. 
https://doi.org/10.1080/03630242.2015.1074640

Tsui, A. O., Brown, W., \& Li, Q. (2017). Contraceptive Practice in sub-Saharan Africa. Population and Development Review, 43(Suppl 1), 166-191.

Weitzman, A. (2017). The effects of women's education on maternal health: Evidence from Peru. Social Science and Medicine, 180, 1-9. https://doi.org/10.1016/j.socscimed.2017.03.004

World Health Organization [WHO]. (2018). Maternal Mortality Fact sheet 2018. Retrieved from World Health Organization website: https://www.who.int/news-room/fact-sheets/detail/maternal-mortality

\section{Copyrights}

Copyright for this article is retained by the author(s), with first publication rights granted to the journal.

This is an open-access article distributed under the terms and conditions of the Creative Commons Attribution license (http://creativecommons.org/licenses/by/4.0/). 